\title{
RICHARD SEEFELDER
}

PROF. R. SeEFElDER, who died on October 12, 1949, was born in Bavaria in 1875, graduated at Munich and started his early medical career as a regular army medical officer in the Saxon army. In 1904 he was seconded to the University Eye Hospital, Leipzig, then under Sattler. His appointment to the chair of Ophthalmology at Innsbruck University, as successor to. Meller, followed his discharge from the army after the first world war in 1919. He stayed at Innsbruck for the rest of his life.

In this country, as indeed almost everywhere in the ophthalmo. logical world, Seefelder was best known as the co-author and editor with Bach of the "Atlas of the Development of the Human Eye". Publishod in 1911, this monumental and most beautifully illustrated work became a classic. In later years he covered the same field, together with that of developmental abnormalities, in two large chapters of Brückner-Schieck's "Kurzes Handbuch der Ophthalmologie" (1931). But his interests were by no means confined to this semi-academic approach to ophthalmology. In his early days at Leipzig he made a valuable contribution to the aetiology and clinical study of jequirity ophthalmia. In the late '20s and early ' 30 s of this century he was amongst the first to establish recognition for Boeck's sarcoidosis as a separate entity in the mass of aetiologically ill-defined chronic affections of the outer and inner eye which, so long as they were not definitely syphilitic, were all somewhat summarily attributed to tuberculosis. At congressional meetings he was a clear, refreshingly uncomplicated, and straightforward speaker.

$$
\text { P. L. K. }
$$

\section{NOTES}

Lectures

A Course of Three Public Lectures entitled "Visual Physiology" will be given by Dr. L. C. Thomson, Ph.D., M.B., B.S., Vision Research Unit, Medical Research Council, Institute of Ophthalmology, on Tuesdays at 5-15 p.m., at the Physiology. Theatre, Gower Street, W.C.1.

Syllabus:-February 7, What are the problems ?; February 14, Colour Vision and the Brightness Mechanism; February 21, Foveal Tritanopia.

\section{Erratum}

B. J. O., Vol. XXXIV, January, 1950. P. 38, para. 2, line 13 , for: "The capillary canula, bent at an angle of about $120^{\circ}$, is drawn from a and cut to approximate to the required size", read "The capillary is compared under the microscope with the central vessels and cut to approximate to the required size". 